\title{
A colocação de pronomes pessoais e possessivos nos diálogos das traduções de Pinocchio para o português do Brasil em 2002
}

\author{
Andréia Guerini e Lucia Jolkesky
}

Resumo: este artigo tem por objetivo apresentar uma reflexão sobre o emprego dos pronomes pessoais e possessivos em diálogos nas falas do personagem Pinóquio em traduções brasileiras de Le Avventure di Pinocchio publicadas no Brasil em 2002.

Palavras-chave: tradução de diálogos, colocação pronominal, legibilidade.

Publicado pela primeira vez em 1883, já em 1891 o livro Le Avventure di Pinocchio foi traduzido para o inglês, e pode ser encontrado em mais de 200 idiomas $^{1}$. Esta obra também tem merecido inúmeras versões no Brasil, desde a pioneira atribuída a Monteiro Lobato, publicada em 1933. Por isso, este artigo tem por objetivo apresentar uma reflexão sobre o emprego dos pronomes pessoais e possessivos em diálogos nas falas do personagem Pinóquio em traduções brasileiras de Le Avventure di Pinocchio publicadas no Brasil em $2002^{2}$. Antes, porém, é importante destacar não só algumas particularidades do português brasileiro, mas também algumas reflexões sobre a função e a tradução de textos infantojuvenis.

\footnotetext{
MACHADO, Ana Maria. Como e por que ler os clássicos universais desde cedo. Rio de Janeiro: Objetiva, 2002, p. 119.

2 Este artigo é uma versão modificada da análise mais ampla que se encontra na dissertação de mestrado de JOLKESKY, L. M. P. V. LEGIBILIDADE DE DIÁLOGOS: $A$ colocação de pronomes nas traduções brasileiras de Pinóquio de 2002. Disponível em: $\langle w w w . b u . u f s c . b r\rangle$ e $\langle w w w . p g e t . u f s c . b r\rangle$.
} 
O português brasileiro (doravante PB), como se sabe, apresenta diferenças entre o padrão culto e o modo coloquial empregado nos diálogos, principalmente com relação ao emprego dos pronomes. Esse fato se torna um problema a ser resolvido pelos tradutores de literatura infantojuvenil, pois os diálogos refletem uma fala entre personagens e, portanto, estão relacionados com a oralidade. Assim sendo, a naturalidade dos mesmos é importante para permitir uma leitura fluente.

Puurtinen (1998, p. 2) e Oittinen (2000, p. 6, 19-21) abordam o tema da legibilidade ${ }^{3}$ e da fluência na leitura $a^{4}$ de literatura infantojuvenil. Oittinen considera a legibilidade fundamental para a compreensão do texto, e Puurtinen a relaciona com a fluência da leitura em voz alta. Ao traduzir para crianças o tradutor tem que fazer adaptações pensando nos futuros leitores. Essas adaptações, quando se trata de um texto já escrito para crianças, não implicam necessariamente em adequações do conteúdo, são modificações que procuram aproximar os leitores ao texto.

$O$ tradutor, para ser leal ao autor e ao leitor, precisa adequar o texto ao nível de compreensão de seus leitores. Essa adequação engloba a pontuação, a familiaridade das palavras e a adaptação às normas linguísticas da cultura-alvo. Uma tradução que não se adapte às normas linguísticas da cultura-alvo pode ter consequências desastrosas, desinteressando as crianças da leitura. É importante lembrar que os livros infantis são feitos para serem lidos por crianças e para crianças. Justamente por isso a colocação pronominal nos diálogos é um fator que pode facilitar ou dificultar tanto a leitura pela criança como aquela que o adulto faz para a criança. $O$ excesso de clíticos pode afetar a naturalidade da fala, pois não é o modo coloquial do PB. Também exige atenção a opção pelo pronome sujeito não lexical, pois no caso da desinência número-pessoal do verbo não permitir a identificação do sujeito, o entendimento pode ficar comprometido.

Afora a questão da domesticação 5 na tradução, existe um compromisso da literatura infantil com a aprendizagem. $O$ seu objetivo primor-

3 Legibilidade é aqui considerada como um dos aspectos da compreensibilidade e está relacionada com a clareza da forma e com a facilidade de leitura em voz alta.

4 Fluência de leitura é aqui considerada a facilidade de leitura tanto silenciosa como em voz alta.

5 Domesticação é aqui considerado o conjunto de modificações que procuram aproximar os leitores ao texto. 
dial pode não ser o de ensinar, mas a literatura infantil dirige-se a uma faixa etária "que é a da aprendizagem e mais especialmente aprendizagem linguística" (SORIANO, 1993, p. 27). Por isso a função pedagógica não pode ser desvinculada da literatura infantil, principalmente do seu papel fundamental como auxiliar na formação dos hábitos da linguagem. $O$ domínio da língua é uma conquista que se faz ao longo de um processo de formação de hábitos que decorrem do uso mesmo da língua. Expressar as idéias de uma maneira clara e objetiva é um recurso ao qual toda criança tem direito; é um dever de quem educa propiciar condições para a aquisição desse recurso, fator de inserção social, independência e defesa dos próprios direitos de cidadão.

Em relação ao estilo do texto, Shavit (1986, p. 28) considera que deve seguir o princípio guia "estilo literário elevado sempre que possível" (nossa tradução) 6 o que na literatura infantil significa "ligado ao conceito didático e à tentativa de enriquecer o vocabulário da criança" (nossa tradução) ${ }^{7}$. Existem, porém, algumas divergências quanto à necessidade de se apresentar à criança somente textos escritos no padrão culto da língua.

Carvalho (1985, p. 211-213) acredita que habituar a criança a expressar-se com clareza não implica no ensino da Gramática, mas faz distinção entre linguagem "correta" e "adulterada", acredita que a "boa" linguagem é um hábito que se forma pouco a pouco à medida que se propicia à criança o contato com a linguagem simples e "correta", seja de forma oral ou através de textos literários. Carvalho é de opinião que a linguagem se "apreende" e se automatiza e, uma vez incorporada uma variante, esta não será substituída por outra.

Possenti (2000, p. 84) também é contrário ao ensino da gramática de forma tradicional, porém, mostra-se menos radical quanto à aceitação de textos escritos numa variante mais informal, e afirma que a criança deve ter o máximo de oportunidades de vivenciar "experiências linguísticas na variedade padrão" para que o domínio progressivo dessa variedade venha substituir formas inadequadas do uso da língua.

Perini (1995, p. 24) pondera que as variedades coloquiais, embora sejam típicas da linguagem oral, podem estar presentes nos diálogos das obras escritas para aparentar mais realidade. Além do que, as variedades da língua falada são objeto das gramáticas descritivas que se preo-

[high literary style whenever possible]

[connected with a didactic concept and the attempt to enrich the child's vocabulary] 
cupam não só em descrever, mas também explicar as línguas como são faladas. Aceitar formas linguísticas mais informais nos textos escritos significa aceitar as regras do português vivo, da língua falada atualmente. Sandroni (1987, p. 89-98) afirma que a maioria das obras publicadas para crianças está escrita no padrão culto da língua e que algumas empregam a forma coloquial nos diálogos reservando a norma culta para a voz do narrador.

Estas considerações sobre as funções e responsabilidades da literatura infantil nos levam a refletir sobre a ação do tradutor. Supõe-se que ele tenha um projeto, mas não podemos descartar as limitações de tempo impostas pelas editoras, como também a função dos revisores de texto que podem efetuar correções que terminam por contrariar a escoIha do tradutor.

O estudo da colocação de pronomes pessoais e possessivos em traduções recentes de literatura infantojuvenil pode nos dar uma idéia de como esta questão tem sido solucionada pelos tradutores. Por isso, examinamos aqui duas traduções de Le avventure di Pinocchio publicadas em 2002. São elas: a de Marina Colasanti, publicada pela Companhia das Letrinhas, e a de Gabriela Rinaldi, publicada pela Iluminuras ${ }^{8}$. A análise privilegiou as falas de Pinóquio, personagem principal, que está presente em quase todos os capítulos e dialoga com todos os demais personagens da história.

Por essas observações constatou-se que nas duas traduções verificam-se empregos dos pronomes pessoais e/ou possessivos de acordo com - que se observa em estudos do português falado no Brasil e em pesquisas no corpus do Google, e também outros empregos que não estão de acordo com esse uso. Poderíamos pensar que isso se deveu à tentativa das tradutoras de tornar a leitura natural retratando a oralidade e não se afastando totalmente do padrão culto da língua, mas nem sempre essas escolhas favoreceram a legibilidade, o que mostra que não foram feitas segundo um critério que almejasse essa finalidade. Os exemplos a seguir ilustram a situação.

Este primeiro exemplo mostra a forma de Pinóquio se dirigir ao pai, que foi retratada de maneira diferente pelas tradutoras:

8 A tradução de Nassetti, também publicada em 2002 pela Martin Claret, não será aqui considerada por causa dos problemas apontados por Denise Bottmann na página eletrônica http://naogostodeplagio.blogspot.com. Consulta realizada em 30 de maio de 2009. 


\begin{tabular}{|l|l|l|}
\hline Collodi, p. 228 & Colasanti, p. 174 & Rinaldi, p. 142 \\
\hline Oh! Babbino mio! & Oh, meu paizinho! & Oh Papai! Finalmente \\
Finalmente vi ho tro- & Até que enfim o encon- & encontrei o senhor! \\
vato! Ora non vi lascio & trei! Agora não vou dei- & Agora não vou deixá-lo \\
più, mai più, mai più! & xá-lo nunca, nunca mais! & nunca mais, nunca mais! \\
\hline
\end{tabular}

Neste excerto a tradução de Rinaldi parece ser a que mais se aproxima do coloquial. "Papai" é a forma de tratamento que as crianças usam para chamar o pai, enquanto que o possessivo "meu" empregado por Colasanti não parece ser adequado à função sintática de vocativo no $P B^{9}$. O objeto direto pronominal em duas frases consecutivas na tradução de Colasanti distancia essa fala do modo coloquial. Rinaldi optou pelo pronome lexical "o senhor" para uma das frases, o que contribui para minimizar essa distância e mostrar o tratamento respeitoso, aspecto que ficou perdido na tradução de Colasanti. O objeto pronominal no português não revela o tipo do tratamento como acontece com o pronome "vi" no texto italiano que indica um tratamento respeitoso ${ }^{10}$.

Já no exemplo a seguir, podemos ver a questão do clítico "lo", não usual no PB:

\begin{tabular}{|l|l|l|}
\hline Collodi, p. 247 & Colasanti, p. 188 & Rinaldi, p. 151 \\
\hline $\begin{array}{l}\text { Davvero?... (...) Se } \\
\text { avessi um milione, } \\
\text { correrei a } \\
\text { portarglielo... }\end{array}$ & $\begin{array}{l}\text { Émesmo? ...(..). Se } \\
\text { eu tivesse um milhão ia } \\
\text { correndo levar para ela. }\end{array}$ & $\begin{array}{l}\text { Verdade?... (...) Se eu } \\
\text { tivesse um milhão, ia } \\
\text { correndo levá-lo para } \\
\text { ela...(...). }\end{array}$ \\
\hline
\end{tabular}

Colasanti e Rinaldi optaram por expressar o sujeito eliminando a possibilidade de dúvidas devido à desinência número-temporal do verbo. Quanto ao objeto direto, as opções foram diferentes: Colasanti tornou essa fala mais próxima do coloquial não expressando o objeto direto $e$ empregando o pronome reto de terceira pessoa preposicionado para obje-

9 NEVES, Maria Helena de M. Possessivos. In: CASTILHO, A. \& BASÍlIO, M. (orgs.). Gramática do Português Falado. Volume III. As Abordagens. Campinas: Unicamp, 1993, p. 182 e 183.

10 SENSINI, Marcello. La grammatica della lingua italiana. Milano: Mondadori, 1997, p. 209. 
to indireto, práticas usuais no PB falado ${ }^{11}$; Rinaldi, por sua vez, optou pelo clítico "lo", o que tornou a sentença gramaticalmente correta, mas afastou-a do PB falado ${ }^{12}$, mas por outro lado usou o pronome reto preposicionado para objeto indireto, o que é usual na língua falada no Brasil, como já citado anteriormente.

Na frase abaixo está um exemplo que permite confrontar o uso do pronome para sujeito ou objeto e a categoria vazia:

\begin{tabular}{|l|l|l|}
\hline Collodi, p. 88 & Colasanti, p. 72 & Rinaldi, p. 64 \\
\hline Le ho perdute! & Perdi! & Eu as perdi \\
\hline
\end{tabular}

Nessa fala de Pinóquio, Colasanti optou pela categoria vazia para sujeito, o que está de acordo com Ilari et al (2002, p. 103) que indicam que o uso do pronome "eu" parece estar vinculado ao acento sobre o mesmo, o que não ocorreria na frase "eu perdi". Quanto ao objeto direto, Colasanti não o expressou, o que é usual no $\mathrm{PB}^{13}$. Rinaldi expressou o sujeito "eu" e empregou o clítico "as", considerado de uso marginal no português falado no Brasil ${ }^{14}$. O resultado foi uma frase gramaticalmente correta e mais próxima ao texto italiano do que ao PB falado.

O próximo exemplo mostra o problema da ausência do sujeito quando a desinência número-pessoal é comum à $1^{1}$ e à $3^{a}$ pessoas:

\begin{tabular}{|l|l|l|}
\hline Collodi, p. 136 & Colasanti, p. 107 & Rinaldi, p. 95 \\
\hline $\begin{array}{l}\text { (..) Ma como avete } \\
\text { fatto a crescere cosi } \\
\text { presto? }\end{array}$ & $\begin{array}{l}\text { (..) Mas como fez } \\
\text { para crescer tão } \\
\text { depressa? }\end{array}$ & $\begin{array}{l}\text { Mas como a senhora } \\
\text { foi crescer tão } \\
\text { depressa? }\end{array}$ \\
\hline
\end{tabular}

11 GALVES, C., Pronomes e categorias vazias em português do Brasil. Cadernos de Estudos Lingüísticos 7. Campinas: UNICAMP: IEL, 1984, p. 107; POSSENTI, Sírio. op. cit., p. 67.

12 GALVES, C. \& ABAURRE, M.B.M. Os clíticos no português brasileiro: elementos para uma abordagem sintático_fonológica. In: CASTILHO, A. \& BASÍLIO, M. (orgs.). Gramática do Português Falado. Volume IV. Estudos Descritivos. Campinas: Unicamp, 2002, p. 293.

13 GALVES, C., op. cit., p. 107.

14 POSSENTI, Sírio. Por que (não) ensinar gramática na escola. $5^{a}$ reimpressão. Campinas: Mercado das Letras: Associação de Leitura do Brasil, 1996/2000. p. 67. 
Aqui, o verbo está com desinência número-pessoal de 3a pessoa, mas Pinóquio dirige-se ao interlocutor, $2^{a}$ pessoa, e somente Rinaldi optou pelo sujeito expresso, o que dá mais clareza ao diálogo. Observe-se que no texto italiano a própria desinência verbal já é indicativa do tom respeitoso que foi retratado apenas por Rinaldi.

O próximo exemplo mostra quão estranho fica o uso da ênclise numa frase imperativa:

\begin{tabular}{|l|l|l|}
\hline Collodi, p. 136 & Colasanti p. 107 & Rinaldi p. 95 \\
\hline Insegnatemelo (...) & Me ensine (...). & Ensine-me , (...). \\
\hline
\end{tabular}

Uma das características do PB é a possibilidade de se iniciarem frases com pronomes átonos, "especialmente com a forma me" (CUNHA; CINTRA, 1965, p. 307) e é o uso habitual para o imperativo ${ }^{15}$. Esta opção de Colasanti apresentou um número de ocorrências muito maior no Google ${ }^{16}$ do que a ênclise. Nesse exemplo, Colasanti esteve mais próxima do modo de falar coloquial no Brasil.

A seguir, temos um caso de colocação pronominal quando o tempo verbal é composto:

\begin{tabular}{|l|l|l|}
\hline Collodi, p. 219 & Colasanti, p. 168 & Rinaldi, p. 108 \\
\hline $\begin{array}{l}\text { Rivendetemi pure: } \\
\text { io sono contento (...). }\end{array}$ & $\begin{array}{l}\text { Pode me vender, } \\
\text { tudo bem (...) }\end{array}$ & $\begin{array}{l}\text { Pode revender-me, } \\
\text { eu fico contente. (...). }\end{array}$ \\
\hline
\end{tabular}

Nessa fala Rinaldi afastou-se da regra normalmente aplicada a esse caso no português brasileiro: "próclise ao verbo que atribui função temática ao pronome" (GALVES; ABAURRE, 2002, p. 286), manteve-se próxima ao texto italiano e o resultado foi uma frase longa que não favorece a leitura em voz alta. Colasanti adotou formas usuais no PB não só com relação à colocação do pronome, mas também pelo uso da expressão "tudo bem". Com isso conseguiu uma frase mais curta e que favorece a leitura em voz alta.

A dúvida que pode surgir devido ao emprego do pronome possessivo "seu" quando este não se refere ao interlocutor é o foco do próximo exemplo:

15 GALVES, C. \& ABAURRE, M. B. M., op. cit., p. 287.

16 JOLKESKY, L. M.P. V., op. cit., p. 54. 


\begin{tabular}{|l|l|l|}
\hline Collodi, p. 92 & Colasanti, p. 74,75 & Rinaldi, p. 66 \\
\hline Davvero? (...) & Verdade? (..) Então, & Verdade! (..) Então \\
Allora, Fatina mia, se & Fadinha querida, se es- & minha Fadinha, se a \\
vi contentate, vorrei & tiver bem para a senho- & senhora concordar, eu \\
andargli incontro! (...) & $\begin{array}{l}\text { ra, quero ir ao encontro } \\
\text { dele! (...) }\end{array}$ & $\begin{array}{l}\text { gostaria de ir ao seu } \\
\text { encontro! (...) }\end{array}$ \\
\hline
\end{tabular}

Cada tradutora usou um modo diferente para Pinóquio dirigir-se à Fada: Colasanti não empregou pronome, Rinaldi usou o pronome possessivo anteposto ao nome, o que pode indicar valor afe tivo ${ }^{17}$, e é o modo empregado em aproximadamente $96 \%$ dos casos pesquisados na linguagem falada ${ }^{18}$. Tanto Colasanti como Rinaldi deixam evidente que Pinóquio trata a Fada por "senhora", refletindo o tratamento respeitoso do texto de Collodi indicado pelo pronome "vi"19. Para expressar o desejo de Pinóquio, Colasanti usou o verbo no presente do indicativo e não usou o pronome lexical, o que não se faz necessário devido à desinência número-temporal permitir a identificação do mesmo. Rinaldi usou o tempo verbal futuro do pretérito refletindo a afabilidade presente no texto de Collodi mostrada pelo verbo no tempo condicional, "vorrei"20, e expressou o sujeito, necessário pois a desinência número-temporal é a mesma para a 1a e 3 pessoas do singular. Outra diferença que se observa é a escolha entre "dele" ou "seu" para pronome de $3^{a}$ pessoa do singular, uma vez que pode causar dificuldades devido ao uso de "seu" tanto para referir-se a um possuidor de 2a pessoa como de 3a pessoa; para evitar ambiguidades, as formas "dele(s)/dela(s)" são um recurso do português ${ }^{21}$. Numa pesquisa sobre a linguagem falada, Negrão \& Müller (1996, p. 142) verificaram que "seu" é empregado em $94 \%$ dos casos de retomada de um sintagma nominal genérico, enquanto "dele" é empregado em $76 \%$ dos casos de retomada de um sintagma nominal específico; assim sendo, a opção de Colasanti, "dele", se mostra mais clara quanto ao sintagma que retoma, o que não acontece com "seu", principalmente porque o nome retomado, "seu pai", se encontra na fala da Fada.

\footnotetext{
CUNHA, C. \& CINTRA, L. op. cit., p. 312 e 314

NEVES, Maria Helena de M., op. cit., p. 184.

SENSINI, Marcello. op. cit., p. 209.

Ibidem, p. 271.

CUNHA, C. \& CINTRA, L., Ibidem, p. 312.
} 
A próxima fala, ao ser lida em voz alta, mostra claramente como a frase gramaticalmente correta se afasta da língua falada e tira a naturalidade do diálogo:

\begin{tabular}{|l|l|l|}
\hline Collodi, p. 178 & Colasanti, p. 137, 138 & Rinaldi, p. 117 \\
\hline E io che son venuto & E eu que fui te pro- & E eu que fui três a \\
cercarti a casa tre & curar em casa três & vezes procurá-lo em \\
volte!... & vezes!... & casa!... \\
\hline
\end{tabular}

Nessa frase de Pinóquio, Colasanti e Rinaldi usaram uma construção topicalizada, comum no português coloquial do Brasil, principalmente "quando o tópico é idêntico ao sujeito da sentença-comentário"22. Com relação ao pronome empregado como objeto do verbo "procurar", Rinaldi optou pelo clítico "lo" que, além de ser de uso marginal no PB falado ${ }^{23}$, pode referir-se tanto a "você/senhor", como a "ele". Colasanti empregou o oblíquo "te", em próclise, forma corrente no PB para expressar a segunda pessoa em posição de objeto (direto ou indireto) 24.

Esses exemplos nos mostram que, com relação aos pronomes, não há um comportamento padrão de cada tradutora, ora é Colasanti que usa o modo coloquial, ora é Rinaldi, e o mesmo ocorre com relação ao padrão culto da língua. É um indício revelador da dificuldade que se apresenta na tradução dos diálogos em virtude da necessidade de possibilitarem uma leitura fluente aparentando naturalidade das falas e, ao mesmo tempo, não se afastarem totalmente do padrão culto em virtude do papel educativo da literatura infantil.

Também permitem identificar duas situações distintas decorrentes do uso dos pronomes de modo não favorável à legibilidade: as que não permitem uma leitura fluente porque o emprego dos pronomes não está de acordo com a língua falada e as que prejudicam a compreensão impedindo a leitura fluente.

As práticas empregadas pelos tradutores que estão na primeira categoria foram: forma de tratamento não usual no Brasil, ausência ou presença do sujeito em desacordo com o PB falado e o emprego do objeto direto/indireto pronominal, principalmente as formas "o/a", "Ihe" e va-

2 PONTES, E. O tópico no português do Brasil. Campinas: Pontes, 1987, p. 26.

23 GALVES, C. \& ABAURRE, M. B. M. Ibidem, p. 293.

24 POSSENTI, Sírio. op. cit., p. 66 e 67. 
riantes, ou "me", "te" de modo não usual no PB, emprego do possessivo de modo não usual. Apesar de estarem de acordo com as regras da gramática tradicional, essas práticas podem prejudicar a fluência da leitura, pois interferem no ritmo natural da língua falada.

Entre os modos de emprego dos pronomes que não favorecem a compreensão estão: sujeito não expresso podendo gerar ambiguidade, uso do pronome "seu/sua" quando o mais determinante seria "dele/dela" e o uso de objeto direto pronominal em situação que pode gerar dúvidas. nadas $^{25}$ :

O quadro a seguir dá um panorama da situação nas traduções exami-

\begin{tabular}{|c|c|c|c|}
\hline \multirow{2}{*}{\multicolumn{2}{|c|}{ Opção }} & \multicolumn{2}{|c|}{ Número de excertos em que ocorre } \\
\hline & & Tradução de Colasanti & Tradução de Rinaldi \\
\hline \multicolumn{2}{|c|}{$\begin{array}{c}\text { Forma de tratamento } \\
\text { não coloquial do filho } \\
\text { para o pai }\end{array}$} & 1 & 1 \\
\hline \multicolumn{2}{|c|}{$\begin{array}{l}\text { Sujeito não expresso } \\
\text { Possível ambiguidade }\end{array}$} & 1 & 2 \\
\hline \multicolumn{2}{|c|}{$\begin{array}{l}\text { Ausência / Presença do } \\
\text { sujeito em desacordo } \\
\text { com o PB falado }\end{array}$} & 1 & 9 \\
\hline \multicolumn{2}{|c|}{$\begin{array}{l}\text { Seu / Sua gerando } \\
\text { ambiguidade }\end{array}$} & 1 & 3 \\
\hline \multirow{2}{*}{$\begin{array}{l}\text { Objeto } \\
\text { pronominal } \\
\text { uso } \\
\text { marginal } \\
\text { no PB } \\
\text { falado }\end{array}$} & Próclise & 3 & 3 \\
\hline & Ênclise & 3 & 11 \\
\hline \multicolumn{2}{|c|}{$\begin{array}{l}\text { Objeto pronominal } \\
\text { Possivel ambiguidade }\end{array}$} & 0 & 2 \\
\hline \multicolumn{2}{|c|}{$\begin{array}{l}\text { Possessivo no grupo } \\
\text { nominal: posposto ao } \\
\text { nome ou não precedido } \\
\text { de artigo }\end{array}$} & 2 & 1 \\
\hline
\end{tabular}

25 JOLKESKY, L. M. P. V.. cp. cit., p. 108. 


\begin{tabular}{|l|c|c|}
\hline $\begin{array}{l}\text { Forma de tratamento } \\
\text { não identificável na } \\
\text { tradução }\end{array}$ & 3 & 3 \\
\hline $\begin{array}{l}\text { Expressões com poucas } \\
\text { ocorrências no Google }\end{array}$ & 8 & 3 \\
\hline $\begin{array}{l}\text { Provável influência do } \\
\text { italiano }\end{array}$ & 5 & 1 \\
\hline Total de casos & 28 & 39 \\
\hline
\end{tabular}

Ao quantificar os dados acima, verifica-se que a tradução de Colasanti apresentou um número menor de ocorrências de colocação pronominal que poderiam dificultar a fluência da leitura. Uma explicação para isso é a informação da própria tradutora a respeito das dificuldades que encontrou ao fazer a tradução de Le Avventure di Pinocchio:

o português tem um fator complicante, que mais se complica no coloquial: o tratamento. Usamos o você misturado com seu e com teu numa grande confusão. Usar nos diálogos a forma gramaticalmente correta 'esfria', endurece o diálogo. Em livros para adultos é absolutamente normal usar a forma errada (digamos assim) que utilizamos ao falar. Mas quando se trata de livros para crianças há sempre a questão da adoção nas escolas, e da exigência gramatical (COLASANTI apud JOLKESKY, 2004, p. 110).

Segundo Colasanti, essa dificuldade foi contornada por um acordo com a editora: "chegamos a um acordo pelo qual os adultos falariam da forma correta, e as crianças falariam da forma usual, cotidiana" (COLASANTI apud JOLKESKY, 2004, p. 110). No entanto, como mostra o exemplo 1, nem sempre essa prática foi adotada.

A tradução de Rinaldi apresentou um número maior desse tipo de ocorrências; uma possibilidade é a própria declaração desta tradutora quanto ao seu projeto de tradução e às dificuldades que encontrou. Procurou traduzir do modo mais fiel possível ao autor $e$, quanto às dificuldades disse que:

a parte mais trabalhosa foi, sem dúvida, verificar se o português que eu usava estava correto do ponto de vista gramatical. Mudar algumas frases que traduzidas literalmente não ficavam claras às vezes também foi difícil, principalmente porque eu tendo a 'italianizar' 
a maneira de escrever, enquanto era necessário 'abrasileirar' o texto (RINALDI apud JOLKESKY, 2002, p. 112).

Na maioria dos casos em que estas tradutoras colocaram os pronomes de um modo que não favoreceu a legibilidade foi porque se mantiveram muito próximas à estrutura da frase no texto italiano, talvez pela familiaridade com a língua devido à própria origem, como explicou Rinaldi. $\mathrm{Na}$ língua italiana a desinência verbal permite identificar a pessoa, como também os pronomes oblíquos apresentam diferenças quando se trata de distinguir um tom respeitoso do falante. Quanto ao pronome possessivo não há uma preferência pela anteposição na língua italiana como ocorre na língua portuguesa. Por exemplo, uma pesquisa no Google ${ }^{26}$ revela praticamente o mesmo número de ocorrências para "figlio mio" "mio figlio" enquanto que "meu filho" ocorre cerca de sete vezes mais que "filho meu". Ao se aproximarem da estrutura da frase em italiano as tradutoras não se aperceberam de que o sujeito não expresso pode gerar ambiguidade quando a desinência número-pessoal é comum à primeira e terceira pessoas e também devido ao uso de você para segunda pessoa. Além disso, algumas vezes, essa proximidade levou-as a usar a colocação dos pronomes oblíquos de modo não usual no PB.

Assim, ao refletir sobre a problemática do modo de uso dos pronomes nas traduções de diálogos constatamos que a proximidade da língua italiana da língua portuguesa e a própria origem italiana dos tradutores pode ter dificultado a percepção dos tradutores quanto ao uso dos pronomes nas traduções aqui examinadas. Além disso, tradutor e editora devem ter um projeto em comum, pois o uso dos pronomes de um modo não habitual nos diálogos causa estranhamento e dificulta a fluência da leitura, pois não se trata de tarefa fácil atender à função da literatura infantil como formadora de bons hábitos de linguagem e ao mesmo tempo propiciar uma leitura que reflita a oralidade e o modo de falar coloquial.

\section{Referências}

CARVALHO, Barbara Vasconcelos de. A literatura infantil: visão histórica e crítica. 4ª edição. São Paulo: Global, 1985.

\footnotetext{
26 Acesso em 04/09/2010.
} 
COELHO, Nelly Novaes. Literatura Infantil: teoria, análise, didática. $6^{a}$ edição. São Paulo: Ática, 1993.

COLLODI, Carlo. As aventuras de Pinóquio. Tradução de Marina Colasanti. São Paulo: Companhia das Letrinhas, 2002.

COLLODI, Carlo. As aventuras de Pinóquio. Tradução de Gabriela Rinaldi. São Paulo: Iluminuras, 2002.

COLLODI, Carlo. Le Avventure di Pinocchio. Firenze: Giunti, 2000.

CUNHA, C. \& CINTRA, L...Nova gramática do português contemporâneo. $2^{a}$ edição. Rio de Janeiro: nova Fronteira, 1985.

GALVES, C. "Pronomes e categorias vazias em português do Brasil". Cadernos de Estudos Lingüísticos 7. Campinas, Unicamp: IEL, 1984.

GALVES, C. \& ABAURRE, M. B. M. "Os clíticos no português brasileiro: elementos para uma abordagem sintático_fonológica". In: CASTILHO, A. \& BASÍLIO, M. (orgs.). Gramática do Português Falado. Volume IV. Estudos Descritivos. Campinas: Unicamp, 2002.

JOLKESKY, L. M. P. V. LEGIBILIDADE DE DIÁLOGOS: A colocação de pronomes nas traduções brasileiras de Pinóquio de 2002, p. 22 e 96. Dis-

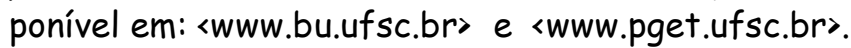

MACHADO, Ana Maria. Como e por que ler os clássicos universais desde cedo. Rio de Janeiro: Objetiva, 2002.

NEGRÃO, V. \& MÜLLER, A. L. "As mudanças no sistema pronominal do português brasileiro: substituição ou especialização de formas?" D.E.L.T.A, Vol. 12 № 1. Resp.: Mary Aizawa Kato. São Paulo: PUC, 1996.

NEVES, Maria Helena de M. "Possessivos". In: Gramática do Português Falado. Volume III: As abordagens. Orgs.: Castilho, A.\& Basílio M. Campinas: Unicamp, 1993, p. 184.

OITTINEN, Riitta. Translating for children. New York/London: Garland, 2000.

PERINI, Mário. A gramática descritiva do português. São Paulo: Ática: 1995.

"Pinóquio" (comentários de Denise Bottmann). Página eletrônica: http:// naogostodeplagio.blogspot.com. Consulta realizada em 30 de maio de 2009. PONTES, E. O tópico no português do Brasil. Campinas: Pontes, 1987.

POSSENTI, Sírio. Por que (não) ensinar gramática na escola. $5^{a}$ reimpressão. Campinas: Mercado das Letras: Associação de Leitura do Brasil, 1996/ 2000. 
PUURTINEN, T. "Syntax, Readibility and Ideology in Children's Literature". In: Meta XLIII, 4, 1998.

SANDRONI, L. De Lobato a Bojunga: as reinações renovadas. Rio de Janeiro: Agir, 1987.

SENSINI, Marcello. La grammatica della lingua italiana. Milano: Mondadori, 1997.

SHAVIT, Z. Poetics of Children's Literature. Athens and London: The University of Geórgia Oress, 1986. In: 〈www.tau.ac.il/ zshavit/>. Acesso em 21/06/05. 